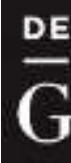

BULGARIAN ACADEMY OF SCIENCES

CYBERNETICS AND INFORMATION TECHNOLOGIES • Volume 16, No 3

Sofia $\bullet 2016$

Print ISSN: 1311-9702; Online ISSN: 1314-4081

DOI: $10.1515 /$ cait-2016-0045

\title{
Business Intelligence System via Group Decision Making
}

\author{
Daniela Borissova ${ }^{1,2}$, Ivan Mustakerov ${ }^{1}$, Dilian Korsemov ${ }^{1}$ \\ ${ }^{1}$ Institute of Information and Communication Technologies, BAS, 1113 Sofia, Bulgaria \\ ${ }^{2}$ University of Library Studies and Information Technologies, 1784 Sofia, Bulgaria \\ Emails:dborissova@iit.bas.bg mustakerov@iit.bas.bg dilian_korsemov@abv.bg
}

\begin{abstract}
In the paper a business intelligence tool based on group decision making is proposed. The group decision making uses a combinatorial optimization modeling technique. It takes into account weighted coefficients for evaluation criteria assigned by decision makers together with their scores for the alternatives in respect of these criteria. The proposed optimization model for group decision making considers also the knowledge level of the group members involved as decision makers. This optimization model is implemented in three-layer architecture of Web application for business intelligence by group decision making. Developed Web application is numerically tested for a representative problem for software choice considering six decision makers, three alternatives and 19 evaluation criteria. The obtained results show the practical applicability and effectiveness of the proposed approach.
\end{abstract}

Keywords: Business intelligence, decision support system, multi-attribute problem, group decision making, Web-based application.

\section{Introduction}

Business decision making nowadays is associated with Business Intelligence (BI) and is a key factor for success in different fields of business decision making. Business intelligence relies on analytics experts with capabilities to support decision processes [4]. Effective BI requires analysis with high level of specialization in analytics due the variety of tools and methodologies used to analyze data. This is why BI mixes data mining, algorithms, visualization and other approaches to help businesses make better decisions [7]. To improve decision making, business decisions, in many organizations, rely on group decision making. Group decision making provides better decisions by involving a group of experts in the decision making process. Group decision problems are multidimensional and the decision has to be based on procedures that explicitly require the integration of a broad set of various and conflicting points of view by means of Group Decision Support Systems (GDSS) defined as a class of electronic meeting systems $[12,13]$. On the other hand, the development of applications needs to follow the business requirements for faster 
delivery to the market at lower costs using the latest infrastructures. This is related to the usage of higher level of abstraction, contributing to improving the productivity and ease of writing complex applications. The advantage of software development as model driven development tools enable these transformations to be specified and executed automatically, using supporting languages and tools for model driven development [3]. The modern BI and analytics platform has emerged to meet new organizational requirements for accessibility, agility and deeper analytical insight [6].

\section{Background research}

Strategic management recognizes business intelligence as a concept and tool to gather and process data from different sources to help in decision making processes. The benefits from use of BI tools improve the profits and gain competitive advantages. Business intelligence could be implemented by different models and techniques to improve the multi-criteria decision making. Depending on the nature of MCDM problems multi-criteria decision making models can be based on fuzzy relations and weighting functions for the criteria to express the preferences of DM [18-23]. Another approach to MCDM is using interactive environment implementing scalarizing and evolutionary methods [8]. In this way the system can be targeted to preferences of different types of users - researchers, educators and business people. In reality, typical BI involves financial analysis, marketing planning, general management, field staffing, upstream supplying, etc. The multidimensional nature of MCDM requires taking into account different points of view about importance of criteria by group decision making [10-16, 23, 25]. A distinctive feature of group decisions is the ability to accumulate the knowledge and skill of variety of experts involved in this process. The Group Decision Making (GDM) combines advantages from both rational and social models and can be implemented in Web based GDSS where criteria descriptions are expressed by linguistic terms $[10,11]$. Different consensus models for group decision making can also be implemented as Web-based applications $[1,16]$. Many techniques are proposed to cope with the Multi-Attribute Decision Making (MADM) problems [24]. The problems of MADM can be approached by combinatorial algorithm for alternatives ranking based on sequentially solving of several multi-criteria optimization tasks [14]. Another approach to MCDM is reducing the given set of alternatives to k-best alternatives that can be used for final selection of the best alternative from the executive managers [2]. The problems of MADM suppose the existence of limited number of alternatives that are usually characterized by conflicting criteria. Taking into account the complexity of real MADM problems, using a group of experts with different skills seems to be a powerful technique for the selection of the most appropriate alternative.

A critical factor for the success of $\mathrm{BI}$ is delivering of analytical information to the end-user via standard Web technologies and enabling the Decision Makers (DMs) to access this information in a unified intuitive way. Many of the proposed Webbased applications for group decision making deals with multiple types of linguistic preference relations or incomplete preferences, or are designed for group decision making in fuzzy environment $[1,23,25]$. In contrast to these approaches, the 
described Business Intelligence Group Decision Support System (BI-GDSS) considers the knowledge level of the experts involved. In the cases, when the members of the group have different level of expertise it is expressed through corresponding weighting coefficients of their opinions. This facilitates the managerial staff to express the direction of company development prospects. For the goal a combinatorial optimization model for group decision making, taking into account the differences in knowledge level of experts is described. This model is implemented in a Web application for BI-GDSS.

\section{Group decision making model with business intelligence}

An important part of the modern decision science is the MADM involving evaluation of multiple attributes of a given set of alternatives. The decision making purpose is to find the most acceptable alternative from a discrete set of feasible alternatives according to the evaluated attributes. For the goal, a group of DMs evaluate alternatives while considering fundamental criteria in alternatives' assessment process. It is assumed that the involved group members have different knowledge, skills, and experience. That implies taking into account the competencies of DMs in the final selection of alternative. A standard feature of MADM methodology is the representation of the input data as a decision table also known as Weighted Decision Matrix (WDM). The multi-attribute decision making can be performed by methods based on the Multi-Attribute Utility Theory (MAUT) or by outranking methods [5]. The paper considers approach based on aggregation of the different criteria into a function, which has to be maximized. The used weights and scores represent the alternatives performance where evaluation criteria are associated with weights within scale 0 to 10. In contrast to authors' previous work [15], the proposed GDM modeling approach considers explicitly not only weight of each DM about criteria importance; DMs evaluations of alternatives via scores; but also and weight coefficients to express the importance of each DM. The corresponding WDM structure is shown in Table 1.

In WDM the higher values of evaluations scores mean a better performance and the final goal is to maximize the outcome of decision (any goal of criteria minimization can be transformed into a maximization goal).

Table 1. Structure of weighted decision matrix

\begin{tabular}{|c|c|c|c|c|c|c|c|c|c|c|c|c|c|}
\hline \multirow{4}{*}{ Criteria } & \multicolumn{3}{|c|}{ Weights of experts } & \multirow{2}{*}{\multicolumn{3}{|c|}{$\begin{array}{c}\text { Alternative } 1 \\
\text { evaluations }\end{array}$}} & \multirow{2}{*}{\multicolumn{3}{|c|}{$\begin{array}{c}\text { Alternative } 2 \\
\text { evaluations }\end{array}$}} & \multirow{4}{*}{$\cdots$} & \multirow{2}{*}{\multicolumn{3}{|c|}{$\begin{array}{c}\text { Alternative } J \\
\text { evaluations }\end{array}$}} \\
\hline & $\mathrm{DM}^{1}$ & $\ldots$ & $\mathrm{DM}^{\mathrm{K}}$ & & & & & & & & & & \\
\hline & \multirow{2}{*}{\multicolumn{3}{|c|}{ Weights of criteria }} & & & & & & & & & & \\
\hline & & & & $\mathrm{DM}^{1}$ & $\ldots$ & $\mathrm{DM}^{\mathrm{K}}$ & $\mathrm{DM}^{1}$ & $\ldots$ & $\mathrm{DM}^{\mathrm{K}}$ & & $\mathrm{DM}^{1}$ & $\ldots$ & $\mathrm{DM}^{\mathrm{K}}$ \\
\hline$c_{1}$ & $w_{1}^{1}$ & $\ldots$ & $w_{1}^{K}$ & $a_{1.1}^{1}$ & $\ldots$ & $a_{1.1}^{K}$ & $a_{1,2}^{1}$ & $\ldots$ & $a_{1,2}^{K}$ & $\ldots$ & $a_{1, J}^{1}$ & $\ldots$ & $a_{1, J}^{K}$ \\
\hline$c_{2}$ & $w_{2}^{1}$ & $\cdots$ & $w_{2}^{K}$ & $a_{2,1}^{1}$ & $\cdots$ & $a_{2,1}^{K}$ & $a_{2.2}^{1}$ & $\ldots$ & $a_{2.2}^{K}$ & $\ldots$ & $a_{2 . J}^{1}$ & $\cdots$ & $a_{2 . J}^{K}$ \\
\hline$\ldots$ & $\cdots$ & $\ldots$ & $\ldots$ & $\ldots$ & $\ldots$ & $\ldots$ & $\ldots$ & $\ldots$ & $\ldots$ & .. & $\ldots$ & $\ldots$ & $\ldots$ \\
\hline$c_{M}$ & $w_{M}^{1}$ & $\ldots$ & $w_{M}^{K}$ & $a_{M, 1}^{1}$ & $\ldots$ & $a_{M, 1}^{K}$ & $a_{M, 2}^{1}$ & $\ldots$ & $a_{M, 2}^{K}$ & $\ldots$ & $a_{M, J}^{1}$ & $\ldots$ & $a_{M, J}^{K}$ \\
\hline
\end{tabular}


Using the structure of WDM shown in Table 1, the following combinatorial optimization model for group decision making is represented:

$$
\operatorname{maximize} \sum_{i=1}^{M} \sum_{k=1}^{K} \alpha^{k} w_{i}^{k} A_{i}^{k},
$$

subject to

$$
\begin{gathered}
\forall i=1,2, \ldots, M\left(\forall k=1,2, \ldots, K, A_{i}^{k}=\sum_{j=1}^{J} a_{i, j}^{k} x_{j}\right), \\
\sum_{j=1}^{\mathrm{J}} x_{j}=1, x_{j} \in\{0,1\}, \\
\alpha^{k} \in(0,1) .
\end{gathered}
$$

The evaluation criteria are represented by set $C$ of $c_{i}$ for $i=\{1,2, \ldots, M\}$ and $C=\left\{c_{1}, c_{2}, \ldots, c_{M}\right\}$. The group of experts involved into decision making process are denoted by $\mathrm{DM}^{k}$ for $k=\{1,2, \ldots, K\}$. Relative importance between criteria $c_{i}$ by different DMs is represented by of corresponding weighted coefficients $w_{i}^{k}$ assigned of each DM toward evaluated criteria. The performance of alternative $J$ (for $j=1,2, \ldots, J)$ against criterion $c_{i}$ by $k$-th DM is denoted by evaluation scores $a_{i, j}^{k}$. The decision variables used to perform the choice of a single alternative are binary integer variables $x_{i}$ assigned to each alternative. Distinguished features of the model (1)-(4) are the coefficients $\alpha^{k}$ that represent the weight of expertise of the involved DMs into the process of group decision making. It should be noted that if the expertise of different DMs is considered with equal importance, the corresponding coefficients $\alpha^{k}$ are set up with equal values.

\section{Numerical illustration}

In order to illustrate the applicability of the proposed group decision making model (1)-(4) described in Section 3 some numerical testing is done. A real case example for software engineering problem adapted from [9] is used where a group of six DMs

\begin{tabular}{|c|c|c|c|c|c|c|c|c|c|c|c|c|c|c|c|c|c|c|c|c|c|c|c|c|c|}
\hline \multirow{3}{*}{$\begin{array}{l}\text { Cri- } \\
\text { teria }\end{array}$} & \multirow{3}{*}{ Description } & \multicolumn{6}{|c|}{ DM weightings } & \multicolumn{6}{|c|}{$\begin{array}{c}\text { Alternative } 1 \\
\text { evaluations }\end{array}$} & \multicolumn{6}{|c|}{$\begin{array}{c}\text { Alternative } 2 \\
\text { evaluations }\end{array}$} & \multicolumn{6}{|c|}{$\begin{array}{c}\text { Alternative } 3 \\
\text { evaluations }\end{array}$} \\
\hline & & \multicolumn{6}{|c|}{ DMNo } & \multicolumn{6}{|c|}{ DMNo } & \multicolumn{6}{|c|}{ DMNo } & \multicolumn{6}{|c|}{ DMNo } \\
\hline & & 1 & 2 & 3 & 4 & 5 & 6 & 1 & 2 & 3 & 4 & 5 & 6 & 1 & 2 & 3 & 4 & 5 & 6 & 1 & 2 & 3 & 4 & 5 & 6 \\
\hline$c_{1}$ & Enforces process accountability & 2 & 4 & 8 & 8 & 6 & 10 & 2 & 4 & 6 & 1 & 1 & 1 & 10 & 5 & 8 & 9 & 9 & 9 & 8 & 4 & 6 & 8 & 9 & 2 \\
\hline$c_{2}$ & Addresses horizontal reporting & 10 & 8 & 8 & 8 & 8 & 4 & 9 & 8 & 7 & 7 & 6 & 7 & 9 & 8 & 7 & 1 & 2 & 10 & 3 & 1 & 5 & 1 & 2 & 10 \\
\hline$c_{3}$ & Addresses vertical reporting & 10 & 10 & 8 & 4 & 8 & 10 & 9 & 2 & 8 & 7 & 6 & 7 & 10 & 4 & 7 & 10 & 9 & 10 & 6 & 5 & 7 & 8 & 8 & 10 \\
\hline$c_{4}$ & Reinforces standards of practice & 6 & 2 & 6 & 6 & 6 & 6 & 10 & 6 & 4 & 4 & 4 & 3 & 10 & 2 & 8 & 7 & 8 & 8 & 8 & 8 & 8 & 6 & 7 & 2 \\
\hline$c_{5}$ & $\begin{array}{l}\text { Effectively handles the } \\
\text { gathering of local requirements }\end{array}$ & 10 & 4 & 10 & 10 & 10 & 8 & 3 & 1 & 9 & 1 & 2 & 1 & 5 & 10 & 7 & 3 & 2 & 7 & 3 & 7 & 2 & 8 & 9 & 9 \\
\hline$c_{6}$ & $\begin{array}{l}\text { Effectively handles the } \\
\text { gathering of Enterprise } \\
\text { requirements }\end{array}$ & 10 & 2 & 8 & 6 & 6 & 8 & 4 & 5 & 3 & 1 & 2 & 1 & 10 & 5 & 7 & 8 & 7 & 7 & 5 & 9 & 2 & 7 & 7 & 3 \\
\hline$c_{7}$ & $\begin{array}{l}\text { Provides project visibility to } \\
\text { contract PMO }\end{array}$ & 6 & 6 & 6 & 8 & 8 & 6 & 8 & 9 & 4 & 2 & 2 & 8 & 9 & 6 & 10 & 7 & 5 & 10 & 7 & 4 & 6 & 7 & 8 & 8 \\
\hline
\end{tabular}
have to take a decision about some software engineering problem. The GDM problem is composed of 19 criteria and three alternatives shown in Table 2.

Table 2. DMs weights for criteria and corresponding alternatives evaluations 
Table 2 (c on tin u e d)

\begin{tabular}{|c|c|c|c|c|c|c|c|c|c|c|c|c|c|c|c|c|c|c|c|c|c|c|c|c|c|}
\hline \multirow{3}{*}{$\begin{array}{l}\text { Cri- } \\
\text { teria }\end{array}$} & \multirow{3}{*}{ Description } & \multicolumn{6}{|c|}{ DM weightings } & \multicolumn{6}{|c|}{$\begin{array}{c}\text { Alternative } 1 \\
\text { evaluations }\end{array}$} & \multicolumn{6}{|c|}{$\begin{array}{c}\text { Alternative } 2 \\
\text { evaluations }\end{array}$} & \multicolumn{6}{|c|}{$\begin{array}{c}\text { Alternative } 3 \\
\text { evaluations }\end{array}$} \\
\hline & & \multicolumn{6}{|c|}{ DMNo } & \multicolumn{6}{|c|}{ DMNo } & \multicolumn{6}{|c|}{ DM No } & \multicolumn{6}{|c|}{ DM No } \\
\hline & & 1 & 2 & 3 & 4 & 5 & 6 & 1 & 2 & 3 & 4 & 5 & 6 & 1 & 2 & 3 & 4 & 5 & 6 & 1 & 2 & 3 & 4 & 5 & 6 \\
\hline$c_{8}$ & $\begin{array}{l}\text { Provides project visibility to } \\
\text { Gov't PMO }\end{array}$ & 10 & 8 & 10 & 8 & 8 & 10 & 6 & 4 & 6 & 2 & 2 & 2 & 8 & 7 & 8 & 7 & 5 & 10 & 5 & 10 & 6 & 7 & 8 & 3 \\
\hline$c_{9}$ & $\begin{array}{l}\text { Provides visibility to local site } \\
\text { leads }\end{array}$ & 6 & 10 & 8 & 10 & 10 & 8 & 5 & 6 & 8 & 2 & 2 & 8 & 6 & 10 & 6 & 2 & 1 & 5 & 6 & 5 & 6 & 5 & 7 & 9 \\
\hline$c_{10}$ & $\begin{array}{l}\text { Provides project management } \\
\text { oversight for projects }\end{array}$ & 4 & 2 & 8 & 6 & 6 & 6 & 2 & 10 & 8 & 1 & 1 & 1 & 4 & 8 & 8 & 7 & 6 & 9 & 10 & 10 & 6 & 9 & 9 & 9 \\
\hline$c_{11}$ & $\begin{array}{l}\text { Provides mechanism to } \\
\text { efficiently assign resources }\end{array}$ & 8 & 8 & 10 & 10 & 10 & 10 & 6 & 5 & 6 & 1 & 1 & 1 & 8 & 9 & 8 & 8 & 9 & 7 & 7 & 4 & 2 & 7 & 8 & 2 \\
\hline$c_{12}$ & $\begin{array}{l}\text { Enforces requirements } \\
\text { management }\end{array}$ & 10 & 4 & 10 & 6 & 8 & 10 & 2 & 8 & 2 & 1 & 1 & 1 & 10 & 1 & 7 & 6 & 6 & 8 & 6 & 6 & 5 & 6 & 6 & 5 \\
\hline$c_{13}$ & $\begin{array}{l}\text { Provides specific requirements } \\
\text { approval and prioritization }\end{array}$ & 10 & 2 & 10 & 6 & 8 & 10 & 1 & 1 & 2 & 1 & 1 & 1 & 8 & 2 & 8 & 7 & 6 & 9 & 5 & 10 & 5 & 7 & 6 & 5 \\
\hline$c_{14}$ & $\begin{array}{l}\text { Promotes de-confliction of } \\
\text { requirements }\end{array}$ & 8 & 6 & 8 & 10 & 10 & 8 & 3 & 6 & 2 & 1 & 1 & 1 & 9 & 5 & 8 & 7 & 8 & 10 & 4 & 4 & 2 & 6 & 6 & 7 \\
\hline$c_{15}$ & $\begin{array}{l}\text { Aligns work to software } \\
\text { resources }\end{array}$ & 4 & 8 & 6 & 8 & 10 & 10 & 5 & 4 & 2 & 1 & 1 & 1 & 8 & 10 & 6 & 8 & 8 & 10 & 4 & 8 & 2 & 8 & 7 & 8 \\
\hline$c_{16}$ & $\begin{array}{l}\text { Manages and operates resources } \\
\text { more efficiently }\end{array}$ & 4 & 4 & 8 & 10 & 10 & 10 & 7 & 8 & 1 & 1 & 1 & 1 & 7 & 9 & 9 & 8 & 7 & 9 & 7 & 10 & 1 & 7 & 8 & 7 \\
\hline$c_{17}$ & $\begin{array}{l}\text { Will be supported by local } \\
\text { customers }\end{array}$ & 6 & 6 & 10 & 10 & 10 & 6 & 10 & 9 & 10 & 7 & 5 & 10 & 3 & 8 & 4 & 5 & 4 & 5 & 5 & 9 & 2 & 8 & 8 & 7 \\
\hline$c_{18}$ & $\begin{array}{l}\text { Development environment is } \\
\text { reachable by all resources }\end{array}$ & 6 & 8 & 8 & 10 & 10 & 6 & 4 & 4 & 1 & 1 & 1 & 1 & 2 & 6 & 1 & 1 & 1 & 1 & 1 & 10 & 1 & 1 & 2 & 1 \\
\hline$c_{19}$ & $\begin{array}{l}\text { Realign resources to handle } \\
\text { surge }\end{array}$ & 4 & 2 & 6 & 10 & 10 & 4 & 4 & 2 & 1 & 1 & 2 & 1 & 8 & 8 & 6 & 7 & 6 & 8 & 3 & 8 & 2 & 6 & 5 & 6 \\
\hline
\end{tabular}

Two set of weighted coefficients are used to express the importance of each DM as shown in Table 3. The best alternative obtained by solution of (1)-(4) for these input data are shown in the last column of Table 3.

Table 3. DMs competency weights and corresponding alternative selection

\begin{tabular}{|c|c|c|c|c|c|c|}
\hline \multicolumn{6}{|c|}{ DMs weights } & \multirow{2}{*}{$\begin{array}{l}\text { The group alternative } \\
\text { selection }\end{array}$} \\
\hline$\alpha_{1}$ & $\alpha_{2}$ & $\alpha_{3}$ & $\alpha_{4}$ & $\alpha_{5}$ & $\alpha_{6}$ & \\
\hline 0.166 & 0.166 & 0.167 & 0.167 & 0.167 & 0.167 & Alternative 2 \\
\hline 0.050 & 0.050 & 0.060 & 0.310 & 0.420 & 0.120 & Alternative 3 \\
\hline
\end{tabular}

The weights of experts can play significant role within process of group decision making. Different competency weights of DMs lead to determination of the Alternative 3 as the best alternative instead of Alternative 2 obtained for equal competency of experts. The testing shows that distribution of evaluations values among alternatives is also important. When alternatives have close evaluation values, the weights of DMs influence considerably the determination of the best alternative. If the difference between alternatives evaluations is more expressed then the optimal solution shows a significant resilience in relation to changing of values of DMs competency weights.

\section{Architecture of Web-based BI-GDSS}

The aim of proposed BI-GDSS is to assist the BI in decision making, considering the described modelling approach in Section 3. The Web-based BI-GDSS can be represented as interactive computer-based information system that combines the 
modern computer capabilities, Internet, database, and decision making methods to support the identification, analysis, formulation, evaluation, and solution of problems by a group in a user-friendly computing environment. The architecture of the proposed GDSS developed as three layer client-server architecture (Fig. 1).

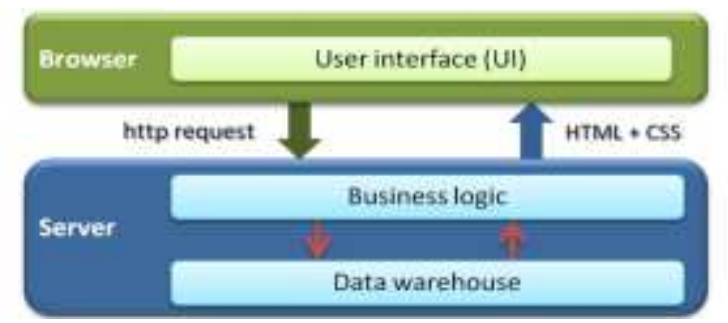

Fig. 1. Architecture of proposed BI-GDSS

The presentation layer contains the User Interface (UI) and manages user interaction. The components of UI are designed for input and output of information encapsulated in the application. The UI has comprises the needed logic for navigation delivered in separate UI components. In most cases, their specific role is to provide the user interface for the data included in the application logic, to interpret user interactions, and to send all requests to the components of presentational logic that define how input data refer to data of the application. The business layer manages the workflow of data and their processing. It communicates with both the presentation layer and the database. The used logic serves to prepare the visualization of data, the validation of data, etc. In this layer the mathematical model (1)-(4) is implemented. The business layer coordinates the application, performs logical decisions, calculations, and processes commands when the user activates a function by UI. The data layer is responsible for access and storage of data. The data layer does not have business logic, but may have logic associated with the processing of data in the data warehouse itself. The access to the data layer is only through the business layer, and then the resulting data is passed back to the user interface of the application.

\section{Implementation of BI-GDSS}

The implementation of Web-based BI-GDSS integrates numerous technologies as HTML, JavaScript, DOM, and XML. All of these technologies together with asynchronous communication are known as Ajax [17]. Thanks to Ajax, a powerful application for the goal of group decision making, using BI can take place. The developed application of BI-GDSS helps to make reasonable decisions in complex situations when a group of DMs have different criteria and alternatives evaluation. An important requirement for the effectiveness of any group decision making system is existence of intuitive interface that provides easy access to the integrated functionality without need of specific mathematical background. The Graphical User Interface (GUI) for entering input data is provided by two access levels administrative level and evaluation level (for DMs). The administrative level enables to setup the parameters of GDM problem as shown in Fig. 2. 


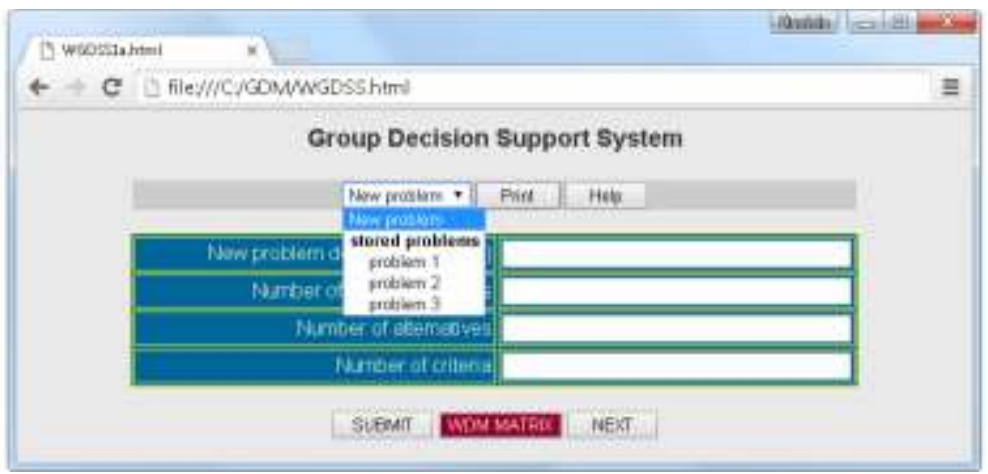

Fig. 2. Administrative screen for entering of the problem parameters

The input data of particular GDM problem include: name of the problem, number of DMs, number of alternatives and evaluation criteria. When these parameters are known the WDM can be generated. The names and weight of DMs is entered together with description of evaluation criteria and alternatives on next screen as shown in Fig. 3.

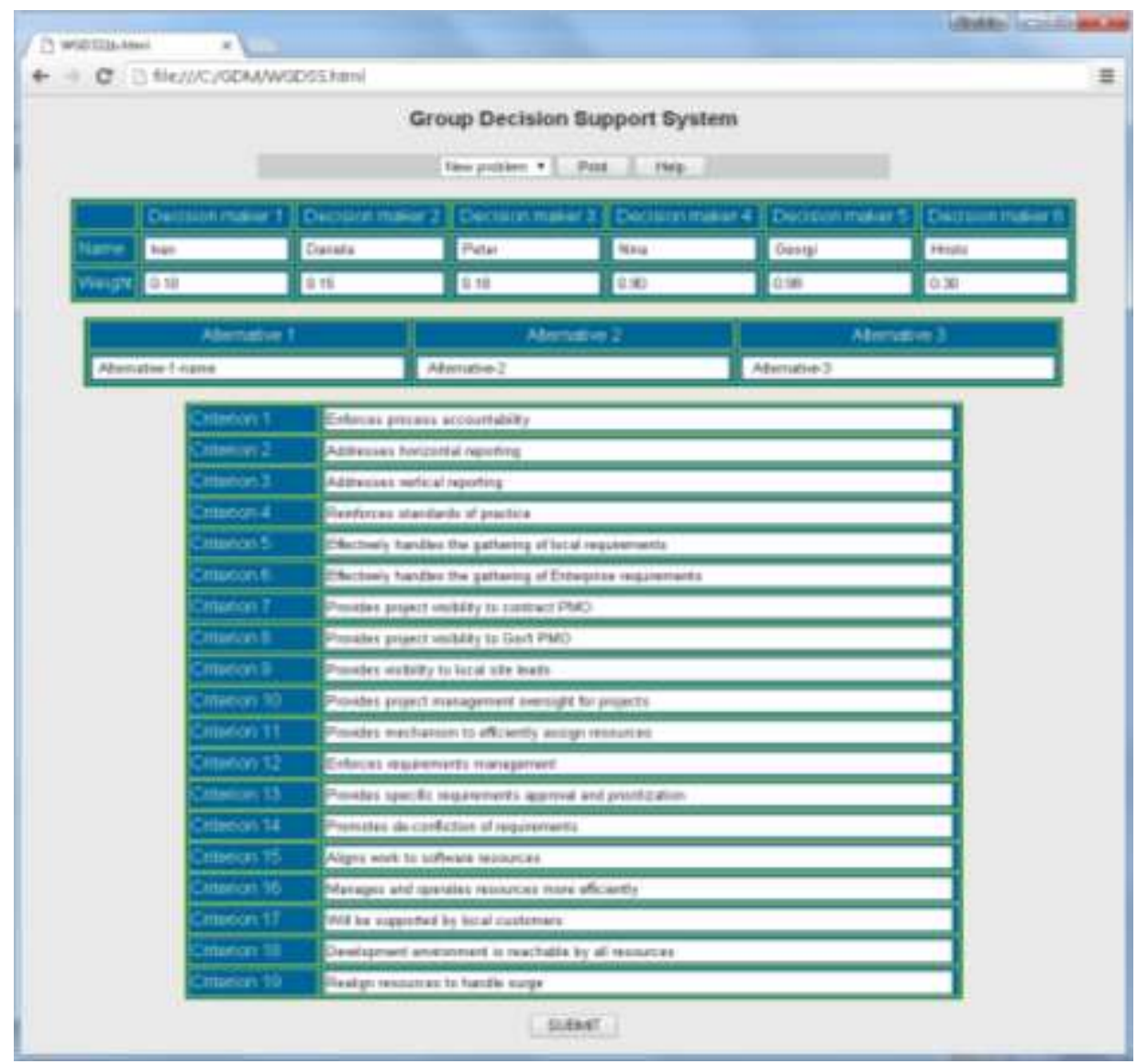

Fig. 3. Administrative screen for entering of DMs, weights, alternatives and evaluation criteria 
In real GDM problems, there might be situations where some of the DMs might not be able to express the preferences between two or more of the available alternatives. This may be due to an expert not possessing a precise or sufficient level of knowledge of part of the problem to be solved, or because that expert is unable to discriminate the degree to which some options are better than others. In such situations, corresponding weighting coefficients reflecting the level of DM knowledge could be used (Fig. 3). The description of different problems for group decision making can be stored in advance and can be invoked by drop-down menu. Selection of stored problem allows loading the WDM with evaluations of DMs. The DM screen for entering the evaluation scores is shown in Fig. 4.

It consists of number of evaluation criteria and is used to express the alternatives performance toward these criteria. Each criterion is assessed by setting the weighting coefficients reflecting its importance from the DM's point of view. It consists of a number of evaluation criteria and is used to express the alternatives performance toward these criteria. Each criterion is assessed by setting the weighting coefficients reflecting its importance from the DM's point of view.

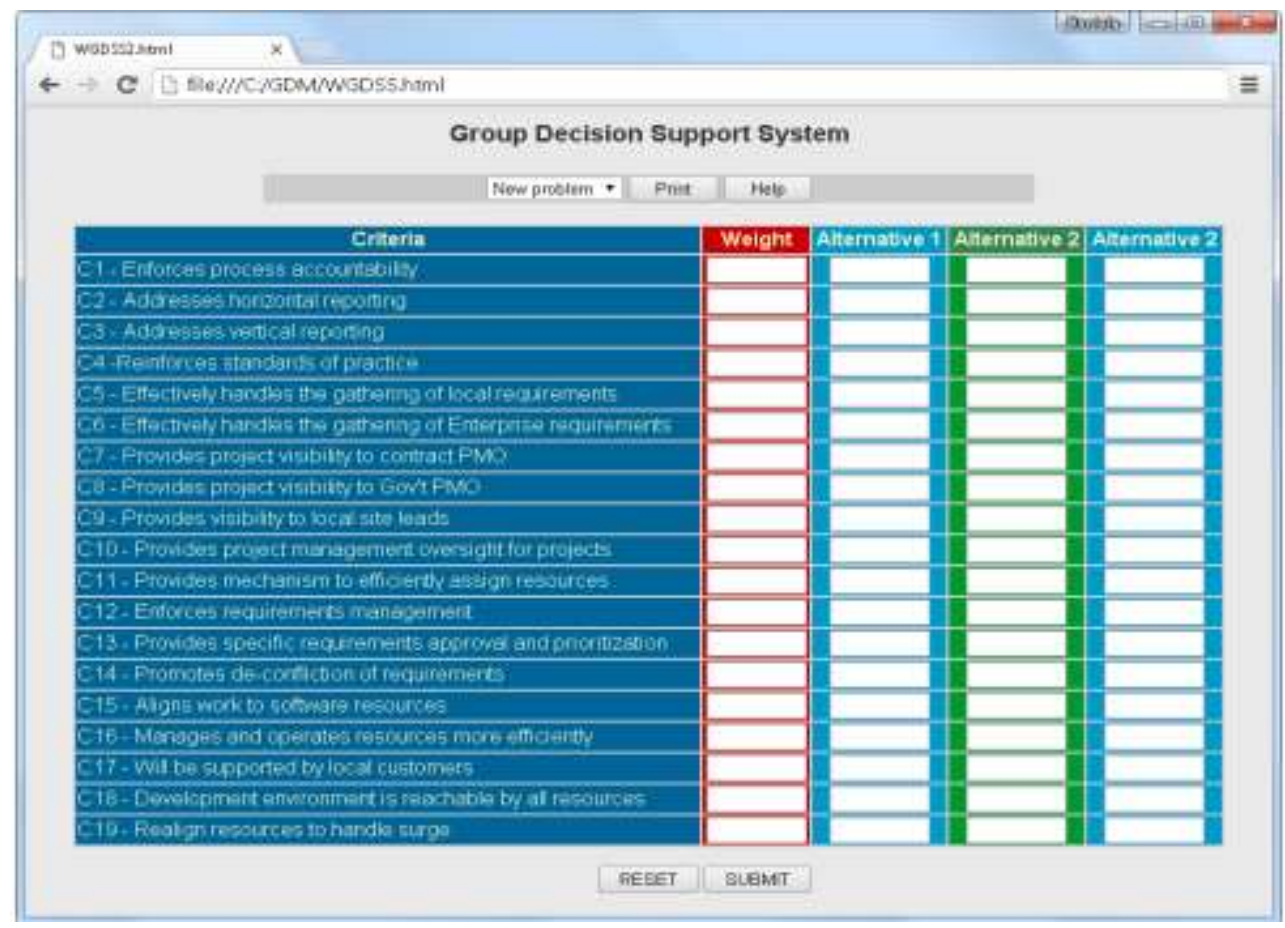

Fig. 4. Screen for entering weights of criteria and evaluations of alternatives by DMs

The entered data of each DM is stored in data warehouse (data layer). All of these evaluations are used to generate WDM on the administrative level and group decision making alternative is determined (Fig. 5). 


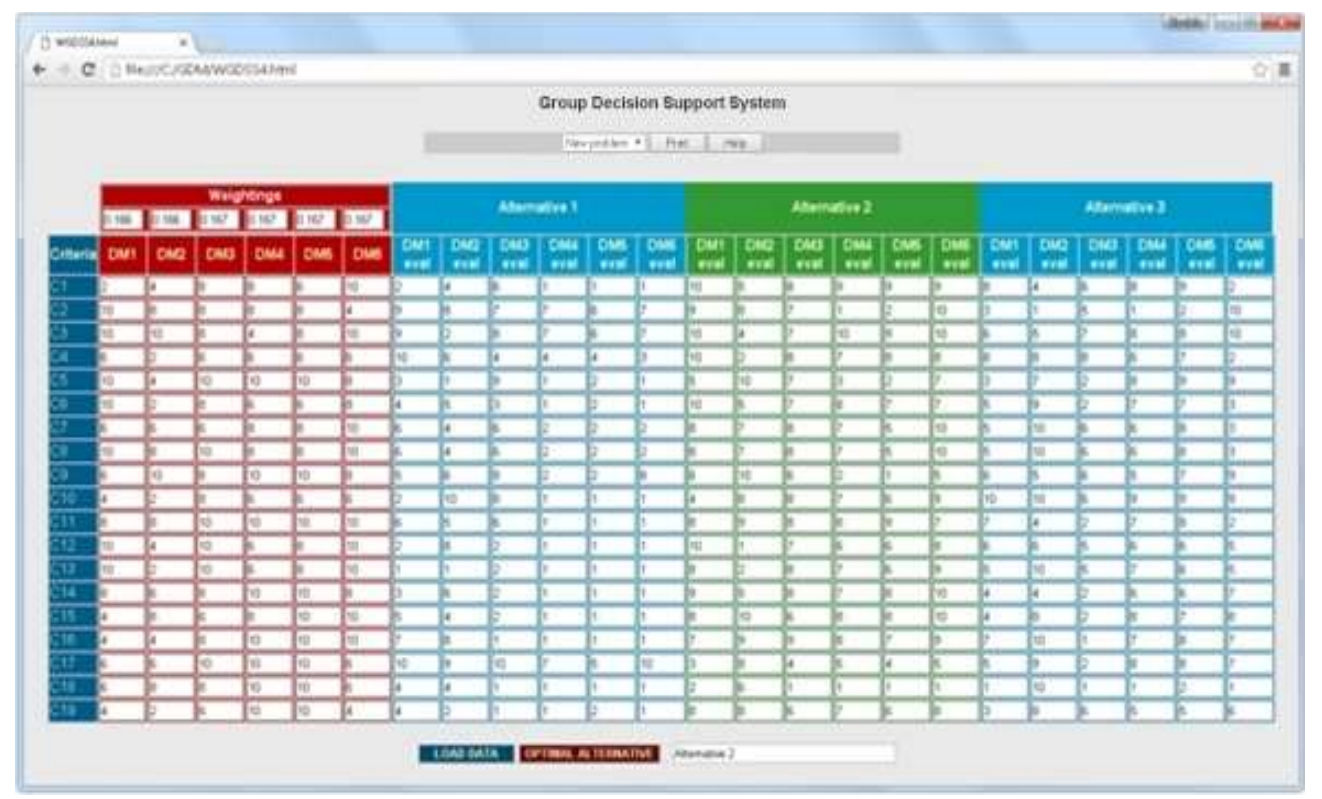

Fig. 5. The screen with WDM and determined group alternative

Involving multiple DMs contribute to preventing prejudice and reducing siding in the decision making process. The degrees of importance of all DMs are determined according to special characteristics of each DM such as: specialization, experience, knowledge, shown to the moment abilities, etc. The final decision is taken by high level executive management by taking into account the determined best alternative as result of using of such mathematically reasoned BI-GDSS.

\section{Conclusion}

A business intelligence group decision support system based on combinatorial optimization model is described. A specific feature of the proposed model is that it takes into account not only evaluations of group members but also the importance of the opinions of all involved experts. The described business intelligence group decision supporting system is realized as Web application and can be used by executive managers as a mathematically reasoned tool. It is based on three levels client-server architecture and two levels of access: 1) administrative - for problem description, and 2) evaluation - for DMs scoring. The proposed modelling approach leads to the formulation of a single criterion mixed integer optimization task whose solution defines the optimal alternative accordingly evaluations of group of experts with different knowledge, experience and importance. This decision making approach is implemented in the business logic layer and solution definition process remains hidden for the user. The testing results show the ease in entering input data via GUI and prove the effectiveness of the proposed approach and its advantages for users without specific mathematical background. As a future development this approach can be modified to reflect other requirements about the decision making process. 


\section{References}

1. Alonso, S., E. Herrera-Vied ma, F. Chi clan a, F. Herrera. A Web Based Consensus Support System for Group Decision Making Problems and Incomplete Preferences. Information Sciences, Vol. 180, 2010, pp. 4477-4495.

2. B o r i s s o v a, D. Group Decision Making for Selection of k-Best Alternatives. - Compt. Rend. Acad. Bulg. Sci., Vol. 69, 2016, No 2, pp. 183-190. ISSN 1310-1331.

3. C a n a d a s, J., J. P a $1 \mathrm{~m}$ a, S. T u n e z. A Model-Driven Method for Automatic Generation of RuleBased Web Applications. - In: Proc. of 5th Workshop on Knowledge Engineering and Software Engineering, Germany, 15 September, Joachim Baumeister, G. J. Nalepa, Eds. 2009.

4. Chaudhuri, S., U. Dayal, V. Narasayya. An Overview of Business Intelligence Technology. - Communications of the ACM, Vol. 54, 2011, No 8, pp. 88-98.

5. F u 1 o p, J. Introduction to Decision Making Methods. BDE-3 Workshop, Washington, 2005. $14 \mathrm{p}$.

6. G a r t n e r. Gartner Says Worldwide Business Intelligence and Analytics Market to Reach \$16.9 Billion in 2016. http://www.gartner.com/newsroom/id/3198917

7. Jiang, L., D. Barone, D. Amyot, J. Mylopoulos. Strategic Models for Business Intelligence. - Lecture Notes in Computer Science, Vol. 6998, 2011, pp. 429-439.

8. Kirilov, L., V. Guliashki, K. Genova, P. Zhivkov, B. Staykov, D. Vatov. Interactive Environment WebOptim for Solving Multiple-Objective Problems Using Scalarizing and Evolutionary Approaches. - Int. J. for Reasoning-Based Intelligent Systems, Vol. 6, 2014, No 2, pp. 4-15.

9. K r a p o h l a, D. Structured Methodology for Group Decision Making. 2013

10. Li u, S., F. T. S. C h a n, W. R a n. Multi-Attribute Group Decision-Making with Multi-Granularity Linguistic Assessment Information: An Improved Approach Based on Deviation and TOPSIS. - Applied Mathematical Modelling, Vol. 37, 2013, pp. 10129-10140.

11. Lu, J., G. Zh a n g, F. W u. Web-Based Multi-Criteria Group Decision Support System with Linguistic Term Processing Function. - IEEE Intelligent Informatics Bulletin, Vol. 5, 2005, No 1, pp. 5-43.

12. M o r a i s, D. C., A. T. A $1 \mathrm{~m}$ e i d a. Group Decision Making for Leakage Management Strategy of Water Network. Resources. - Conservation and Recycling, Vol. 52, 2007, pp. 441-459.

13. M or a i s, D. C., A. T. A $1 \mathrm{~m}$ e i d a. Group Decision Support System Based on PROMETHEE Integrated with Problem Structuring Approach. - Group Decision and Negotiation, Stockholm, Sweden, 2013, pp. 17-20.

14. Mustakerov, I., D. B oris sova. A Combinatorial Optimization Ranking Algorithm for Reasonable Decision Making. - Comptes Rendus de l'Academie Bulgare des Sciences, Vol. 66, 2013, No 1, pp. 101-110.

15. Must a k e rov, I., D. B or is s o v a. A Web Application for Group Decision-Making Based on Combinatorial Optimization. - In Proc. of 4th International Conference on Information Systems and Technologies, 2014, pp. 46-56.

16. P a lo mares, I., R. M. Rodriguez, L. Martinez. An Attitude-Driven Web Consensus Support System for Heterogeneous Group Decision Making. - Expert Systems with Applications, Vol. 40, 2013, No 1, pp. 139-149.

17. P a t e 1, S. K. Developing Responsive Web Applications with AJAX and jQuery. Packt Publishing, 2014.

18. P e n e v a, V., I. P o p c h e v. Fuzzy Multi-Criteria Decision Making Algorithms. - Compt. Rend. Acad. Bulg. Sci., Vol. 63, 2010, No 7, pp. 979-992.

19. P e n e va, V., I. P o p ch e v. Models for Fuzzy Multicriteria Decision Making Based on Fuzzy Relations. - Comptes Rendus de l'Academie Bulgare des Sciences, Vol. 62, 2009, No 5, pp. 551-558.

20. Pen e va, V., I. P o p ch e v. Multicriteria Decision Making by Fuzzy Relations and Weighting Functions for the Criteria. - Cybernetics and Information Technologies, Vol. 9, 2009, No 4, pp. 58-71. 
21. P e n e v a, V., I. P o p c h e v. Models for Decision Making by Fuzzy Relations and Fuzzy Numbers for Criteria Evaluations. - Compt. Rend. Acad. Bulg. Sci., Vol. 62, 2009, No 10, pp. 1217-1222.

22. R ou hani, S., M. Gha z a $\mathrm{f}$ ari, M. J a f ari. Evaluation Model of Business Intelligence for Enterprise Systems Using Fuzzy TOPSIS. - Expert Systems with Applications, Vol. 39, 2012, No 3, pp. 3764-3771.

23. S u b s o r n, P., J. X i a o, K. S i n g h. A Web-Based Application of Group Decision Making in a Fuzzy Environment. - In: Proc. of 5th Int. Conf. on Electrical Engineering/Electronics, Computer, Telecommunications and Information Technology, Vol. 1, 2008, pp. 17-20.

24. Tze n g, G. H., J. J. H u a n g. Multiple Attribute Decision Making: Methods and Applications. Taylor \& Francis Group, 2011.

25. X u, Z. Group Decision Making Based on Multiple Types of Linguistic Preference Relations. Information Sciences, Vol. 178, 2008, No 2, pp. 452-467. 